\title{
Amsterdam-Cambridge-UNC Charlotte Symposium 2008 Real Estate Portfolio \& Risk Management
}

\section{Editors' Introduction}

\author{
Richard Buttimer • Erasmo Giambona • \\ Kanak Patel
}

Published online: 5 May 2009

(C) Springer Science + Business Media, LLC 2009

This Special Issue of the Journal of Real Estate Finance and Economics presents papers presented at the Cambridge-Amsterdam UNC Charlotte Symposium, hosted by the Finance Group of University of Amsterdam Business School in the facilities of Amsterdam School of Real Estate, Netherlands, in June 2008. Twelve papers were presented at the Symposium of which eight are published this Issue.

Patel, Pereira and Zavodov in "REITs Discount to NAV \& Risk Premium: Too Low? Too high?" study whether the REITs discount to net asset value (NAV) can be explained by an unduly lower risk premium applied to private real estate valuation relative to the risk premium generally applied for REITs. The private real estate market does not account in the valuation process for categories of risk inherent to real estate properties, such as vacancy risk, tenant credit risk, liquidity as well as the bundle of options typically embedded into lease contracts. By contrast, the public real estate market adequately assesses these sources of risk. Using data for the UK REIT property market, the paper finds that discount to NAV is mean reverting. Related to this, the authors find that the risk premium extracted from private property valuation is not sensitive to measures of macroeconomic condition while the risk premium extracted from public markets is sensitive to these measures.

\footnotetext{
R. Buttimer

Department of Finance, University of North Carolina at Charlotte, 9201 University City Blvd, Charlotte, NC28223, USA

e-mail: buttimer@uncc.edu

E. Giambona

University of Amsterdam, Roetersstraat 11, 1018 WB Amsterdam, The Netherlands

e-mail: e.giambona@uva.nl

K. Patel $(\bowtie)$

Department of Land Economy, University of Cambridge, 19 Silver Street, Cambridge CB3 9EP, UK e-mail: kp10005@cam.ac.uk
} 
Depken II, Hollans and Swidler, in "Property Flipping and House Price Risk", analyze the flipping activity in Las Vegas. Flipping may be one reason behind the "bubble" in certain housing markets. Rapid home price appreciation may lead to an increase in flips which in turn leads to increased demand for housing and even higher home prices. The authors compare flipped house prices in Las Vegas from 1994 through mid-2007 to contemporaneous prices of homes that are not part of a flip and discount/premium on flip sale. The analysis also investigates flipping volume over time and correlates this activity with price appreciation in the local real estate market. The median duration between the buy and sell-side of a house flip changes dramatically during the most active period of house flipping during the sample period. For flips sold in $2004 q 4$, the median duration of a house flip is only 9 months compared to 1.2 years when flipping activity subside. At the height of the housing boom in 2004, a typical flip produced an annual rate of return exceeding $60 \%$, which translates to economic profits of nearly $20 \%$. The evidence suggests that flipping activity, the duration of a flip and the price appreciation of all residential property are inextricably linked together.

Clark and Coggin, in "Trends, Cycles and Convergence in U.S. Regional House Prices", analyze the time series properties of trends, cycles and convergence of U.S. regional house prices. The authors fit a classic business cycle model, the smooth trend plus cycle model, to 9 OFHEO regions and 2 factors and test to see if the regions and factors are converging to a common growth path, allowing for the possibility of a structural break. The Factor 1 includes the 4 lowest ranked regions by mean price level for the full period (1975/1-2005/2), and Factor 2 includes the 5 highest ranked. West South Central (WSC) was deleted due to its distinction as an outlier in the factor analysis. The tests for regional convergence take the form of bivariate, error correction ADF unit root tests on regional differences. The bivariate unit root tests suggest that, before and after allowing a single structural break, there is little or no evidence of any type of convergence for the regions in Factor 1, and more substantial evidence of relative convergence for the regions in Factor 2. An examination of the growth rates for the regions and factors confirm that both regional factors experienced significant growth from the early to mid-1990s on, and further revealed that the growth rates for Factor 2 (and its regions) are significantly larger than those for Factor 1.

Calcagno, Fornero and Rossiz, in "The Effect of House Prices on Household Consumption in Italy", study the marginal propensity of consumption (MPC) from housing wealth for Italian households. Since real estate is the most important component of households' wealth this represents a key step in understanding the effects of changes in wealth on consumption choices. The study focuses on the microeconomic data contained in the Bank of Italy's Survey of Households Income and Wealth (SHIW). Results suggest that the propensity to consume based on real estate assets does not differ much across age categories, while the MPC out of real estate capital gains is more pronounced for older cohorts. The results suggests that consumption is more reactive to real wealth appreciation than to financial wealth, with an MPC almost twice that of financial assets. Considering the endogeneity of homeownership does not change the results, confirming an MPC out of real estate capital gains between 1 and 2 cents. 
Jou and Lee, in "How does a development moratorium affect development timing choices and land values?", investigate effect of a development moratorium on the development timing choice and the net value of developed property in a framework where both the value of developed property evolves stochastically and the development costs are fully irreversible. The interaction of irreversibility and uncertainty confers the developer two American-type call options, which the developer must include as the opportunity costs when deciding whether to develop vacant land before the development moratorium is imposed. The developer will exercise the development option if the net value from development exceeds the combined value of these two options. Otherwise, the developer will delay exercising the development option after the moratorium expires. Based on some simplified assumptions, the authors demonstrate that a developer will wait longer to exercise the development option if the regulator either delays the beginning date or puts forward the end-date of the moratorium, if the developer is far-sighted, or if the developer incurs larger development costs. The development moratorium is not an effective policy to curb growth because it accelerates development, and thus yields a result just contrary to its original goal.

Arbel, Ben-Shahar and Sulganik, in "Mean Reversion and Momentum: Another Look at the Price-Volume Correlation in the Real Estate Market" use real options approach to examine the optimal time of purchase. In the model, prospective first-time home buyers act under the perception that prices follow a (stochastic) mean reverting process and where developers offer their stock of housing assets at the given market price. The authors provide a simple and intuitive rationale for the correlation between the price yield and the transaction volume in the real estate market. An empirical analysis, based on the monthly time series of the housing price index and the sales of new construction in Israel from January 1998 to June 2007, provides evidence that while consumers' demand pattern is simultaneously consistent with the belief in both momentum and mean reversion processes, the effect of the latter generally dominates. An important implication that emerges from the results is that, given consumers' perception of mean reversion and momentums in housing prices, developers can better assess future demand depending on past and ongoing prices.

Brounen and Jennen, in "Asymmetric Properties of Office Rent Adjustment" specify an asymmetric office rent adjustment model such that when vacancy rates are below their long term average office rents react significantly stronger to positive changes in office employment compared to periods of abundant supply. The empirical analysis uses a unique panel set of quarterly data that covers fifteen metropolitan areas (MSA's) in the United States over the period 1990-2007. The authors group MSA's with multi dimensional scaling based on similarity in rent-or employment dynamics and run panel data regressions based on these clusters. The results show that changes in office employment have a larger impact on office rents when vacancy rates are below their long term average, which implies that new demand does not influence rents in a symmetric way but is most influential when prevailing vacancy rates are relatively low. The authors also find that there are large differences in model fit across the clusters examined.

Ling, Marcato and McAllister, in "The Dynamics of Asset Prices and Transaction Activity in Illiquid Markets: The Case of Private Commercial Real 
Estate", investigate the empirical relationship between asset prices in the UK private commercial real estate market and capital flows and turnover. The conditional covariation results from panel VAR estimation, using capital appreciation and percentage capital flows as endogenous variables, do not support the widely-held belief among practitioners that capital flows are a prime determinant of price movements. The results provide only limited evidence of a role for individual quarterly lags of capital flows and turnover in explaining the variation of capital appreciation rates. Whilst there is evidence of return chasing in the first quarter, this finding may be due to the delayed recording of flows relative to returns given the difficulties of market entry with a one quarter lag. 